\title{
Acute changes in serum immune markers due to swimming in a chlorinated pool
}

Jelle Vlaanderen ${ }^{1}$, Karin van Veldhoven ${ }^{2}$, Laia Font-Ribera ${ }^{3,4,5,6}$, Cristina M Villanueva ${ }^{3,4,5,6}$, Marc Chadeau-Hyam ${ }^{2}$, Lützen Portengen ${ }^{1}$, Joan O. Grimalt ${ }^{7}$, Christian Zwiener $^{8}$, Dick Heederik ${ }^{1}$, Xiangru Zhang $^{9}$, Paolo Vineis ${ }^{2,10}$, Manolis Kogevinas ${ }^{3,4,5,6}$, Roel Vermeulen ${ }^{1}$

1. Institute for Risk Assessment Sciences, Utrecht University, Utrecht, The Netherlands.

2. Imperial College London, London, UK.

3. ISGlobal, Centre for Research in Environmental Epidemiology (CREAL), Barcelona, Spain

4. Universitat Pompeu Fabra (UPF), Barcelona, Spain

5. CIBER Epidemiología y Salud Pública (CIBERESP), Barcelona, Spain

6. IMIM (Hospital del Mar Medical Research Institute), Barcelona, Spain

7. Department of Environmental Chemistry, Institute of Environmental Assessment and Water Research (IDAEA-CSIC), Barcelona, Spain

8. Environmental Analytical Chemistry, University of Tuebingen, Germany

9. Department of Civil and Environmental Engineering, Hong Kong University of Science and Technology, Hong Kong, China

10. Human Genetics Foundation, Turin, Italy

Running title: Acute changes in serum immune markers due to swimming in a chlorinated pool

Financial support: This work was supported by the grant FP7 of the European Commission 'Enhanced exposure assessment and omic profiling for high priority environmental exposures in Europe' (no. 308610).

Corresponding author: Jelle Vlaanderen, Division of Environmental Epidemiology, Institute for Risk Assessment Sciences (IRAS), Utrecht University, PO Box 80178, 3508 TD, Utrecht, The Netherlands. Tel +31 30253 5947. E-mail: J.J.Vlaanderen@uunl

Word count: 3947

Total number of figures and tables: 4 tables; 1 figure

Conflict of interest: None declared 


\section{Abstract}

\section{Background}

Exposure to disinfectants and disinfection byproducts (DBPs) due to swimming in chlorinated water has been associated with allergic and respiratory health effects, including asthma.

\section{$\underline{\text { Objectives }}$}

Biological mechanisms contributing to these associations are largely unknown. We hypothesized a potential pathway involving modulation of the immune system.

\section{Methods}

We assessed levels of immune markers (CCL11, CCL22, CXCL10, CRP, EGF, GCSF, IL-8, IL-17, IL-1RA, MPO, VEGF, Periostin) in serum collected from 30 women and 29 men before and after 40 minutes of swimming in a chlorinated pool. Exposure to DBPs was assessed by measuring bromodichloromethane, bromoform, chloroform, and dibromochloromethane in exhaled breath before and after swimming. Covariate data including information on physical activity was available through questionnaires and measurements. We assessed the association between indicators of swimming in a chlorinated pool and changes in serum immune marker concentrations using linear regression with bivariate normal distributions and adjusted for multiple comparisons by applying the Benjamini-Hochberg procedure.

\section{$\underline{\text { Results }}$}

We observed a significant decrease in serum concentrations of IL-8 (-12.53\%; q=2.00e-03), CCL22 (7.28\%; q=4.00e-04), CCL11 (-7.15\%; q=9.48e-02), CRP (-7.06\%; q=4.68e-05), and CXCL10 (-13.03\%; $q=6.34 e-14)$ and a significant increase in IL-1RA (20.16\%; $q=4.18 e-06)$ from before to after swimming. Associations with quantitative measurements of DBPs or physical activity were similar in direction and strength. Most of the observed associations became non-significant when we adjusted the effects of exposure to DBPs for physical activity or vice-versa.

\section{Conclusions}

Our study indicates that swimming in a chlorinated pool induces perturbations of the immune response through acute alterations of patterns of cytokine and chemokine secretion. The observed effects could not be uniquely attributed to either exposure to DBPs or physical activity. Evidence in the literature suggests that observed decreases in immune markers are possibly due to an immunosuppressive effect of DBPs, while the increase in IL-1RA might be due to physical activity. 
Key words: Immune markers, disinfection byproducts, DBPs, blood 


\section{Introduction}

Even though the beneficial effect of swimming as a form of physical activity on human health is undisputed, concerns have been raised with regards to potential negative effects on human health of swimming in pools in which water disinfectants are applied. Disinfectants such as chlorine react with organic matter in the water creating a range of disinfection by-products (DBPs), some of which (especially trichloramine) have been linked with chronic allergic and respiratory health effects, including asthma, in epidemiological studies (Villanueva et al., 2015; Villanueva and Font-Ribera 2012). Biological mechanisms contributing to these observed associations are largely unknown though might involve modulation of the immune system.

Two studies previously assessed the effect of swimming in chlorinated pools on acute changes in immune marker concentrations. Font-Ribera et al. (2010) assessed a suite of markers (RANTES (regulated upon activation, normal T-cell expressed, and secreted), vascular endothelial growth factor (VEGF), tumor necrosis factor (TNF), interleukin (IL) 12p70, IL-4, IL-8, IL-10, interferon-gamma (IFN- $\gamma$ ), and IFN- $\gamma$-induced protein 10 (IP10)) in exhaled breath condensate of nonsmoking adults, collected before and after for 40 minutes of swimming in a chlorinated pool. No significant change in any of the immune markers was observed. A significant change in lung damage marker club cell secretory protein 16 (CC16) levels in serum was observed. The authors mentioned that the concentrations of the immune markers in exhaled breath condensate was low and indicated that further validation of using these markers assessed in exhaled breath condensate as indicators of acute inflammation was needed (Font-Ribera et al., 2010). Pedersen et al. (2009) observed no significant changes in lung function, exhaled NO, $\mathrm{pH}$ of exhaled breath condensate, and cellular composition of sputum of 45 minutes of swimming in a chlorinated swimming pool. One study very similar in design to the study by Font-Ribera observed no significant associations between the effect of swimming in a chlorinated pool on oxidative stress and lung damage markers (serum surfactant proteins A and B) (Llana-Belloch et al., 2016).

Evidence for potential immunotoxic effects of DBPs is available from a handful of animal studies (Auttachoat et al., 2009; French et al., 1999; Munson et al., 1982), while studies among humans exposed to halocarbons that are structurally very similar to DBPs also provide evidence for immunotoxic effects (Bassig et al., 2013; Griffin et al., 2000; lavicoli et al., 2005; Weber et al., 2003).

In addition to DPBs, physical activity might also have an effect on the immune system. A bout of physical activity has been reported to induce an anti-inflammatory environment including acute elevations in production of interleukin 6 (IL-6) from muscle tissue, stimulating the production of antiinflammatory cytokines such as IL-1 receptor antagonist (IL-1RA), and downregulation of the number 
of monocytes in blood reducing the production of pro-inflammatory cytokines (Gleeson et al., 2011). Long-term exposure to regular bouts of physical activity has been linked to immunosuppression thought to be induced by the anti-inflammatory effects of exercise (Gleeson et al., 2011).

In this study we assessed the impact of 40 minutes swimming in a chlorinated pool on changes in a set of 13 serum immune markers. We attempted to disentangle the effects of physical activity and exposure to DBPs on the immune markers by quantitative assessment of both markers of exposure to DBPs and physical activity and by controlling potential confounding factors such as age, sex, and Body Mass Index (BMI). 


\section{Methods}

\subsection{Design}

We recruited 59 nonsmoking adults through open advertisements at local universities. A screening questionnaire was used to verify eligibility among subjects (nonsmoking, non-professional swimmers, $18-40$ years of age). Participants were asked to swim for 40 minutes at a calm pace in an indoor 25 meter long chlorinated swimming pool in Barcelona, Spain. Participants did not swim during the week before the swimming session and did not shower or conduct intense physical activity on the day of the study. Up to four participants were evaluated between 09:00 and 14:00 each day (before lunch) in June, September-December 2013. Exhaled breath and blood were collected before and after the subjects swam in the chlorinated pool in a room inside the sports center. The study was approved by the ethics committee of the research center following the international regulations, and all volunteers signed an informed consent before participation.

\subsection{Assessment of physical activity}

Physical activity was estimated by measuring the distance swum by each participant, calculating energy expenditure (in kilocalories) using the swimming speed and the weight of the participant, assuming that swimming at $46 \mathrm{~m} / \mathrm{min}$ equals 8.3 metabolic equivalent tasks (METs; kilocalories per kilogram per hour) (Ainsworth et al., 2000):

$$
\text { Kcal }=\text { weight }(\mathrm{kg}) \times \frac{\text { distance swam }(\mathrm{m})}{\text { minute }} \times \operatorname{swimming} \text { duration }(\mathrm{hr}) \times 8.3\left(\frac{\mathrm{kcal} / \mathrm{kg}}{\mathrm{hr}}\right) / 46(\mathrm{~m} / \mathrm{min})
$$

Study participants also wore a RCX5 heart rate (HR) monitor while swimming (Polar, Kempele, Finland). We calculated the percentage of monitored heart rate values during swimming that was higher than 69 percent of the individual theoretical maximum heart rate according to sex and age, indicating high intensity physical activity (\%HR; 220-age for males, 206-0.88*age for females) (Gulati et al., 2010) . Two participants did not register HR data. We imputed the missing values with the median value of the \%HR calculated for the remaining study participants.

\subsection{Markers of exposure to DBPs}

We measured concentrations of four trihalomethanes (THMs)-chloroform $\left(\mathrm{CHCl}_{3}\right)$, bromodichloromethane (BDCM), dibromochloromethane (DBCM), bromoform $\left(\mathrm{CHBr}_{3}\right)$-in exhaled breath before swimmers entered the swimming pool and right after (median 4 minutes) they left the 
pool (median 4 minutes). We used the THMs as surrogate for DBP exposure because they are easily measured in exhaled breath. Measurement of THMs in exhaled breath for this study has been described before (Font-Ribera et al., 2016). Briefly, exhaled breath samples were collected using a portable system for exhaled breath sampling (Bio-VOC ${ }^{\text {TM }}$ Sampler, Markes International Ltd, UK). A total of $600 \mathrm{~mL}$ exhaled breath volume was collected. THM concentration were detected using a Gas Chromatograph 7890 (Agilent Technologies) coupled to Mass Spectrometer 5975C Inert XL MSD with a source in Electron Impact Mode (Agilent Technologies). Concentrations were expressed as micrograms per cubic meter.

In addition swimming water concentrations of a range of DBPs, including the THMs measured in exhaled breath, were measured on the days the study was conducted. A detailed description of sampling and analytical methods for DBPs in the poolwater in this study was provided in Font-Ribera et al. (2016).

To measure trichloramine, air samples were collected every day with a sampling pump at a constant flow rate of $1.2 \mathrm{~L} / \mathrm{min}$ for $115 \mathrm{~min}$ within 1 meter of the pool at a height of $60 \mathrm{~cm}$ above the water level. Trichloramine was collected on a quartz fibre filter, reduced to chloride ions and subsequently analyzed by ion chromatography. Further details on the applied methods are provided in Jacobs et al. (2007).

\subsection{Immune markers}

Serum samples were collected directly before swimming and 2 hours after swimming and were coldstored within $2 \mathrm{~h}$ after collection. A panel of 23 immune markers in serum was assessed using an R\&D Systems (Abingdon, UK) Luminex ${ }^{\circledR}$ screening assay according to the protocol described by the manufacturer. The panel includes Interleukin (IL)-13, IL-1rA, IL-4, IL-5, IL-6, IL-8, IL-10, IL-13, IL-17, TNF- $\alpha$, Epidermal Growth Factor (EGF), Macrophage Inflammatory Protein 1 beta (MIP1 beta), chemokine (C-X-C motif) ligand 1 (CXCL1), myeloperoxidase (MPO), C-X-C motif chemokine 10 (CXCL10), vascular endothelial growth factor (VEGF), C-C motif chemokine 22 (CCL22), Periostin, chemokine (C-C motif) ligand 2 (CCL2), Basic fibroblast growth factor (FGF basic), granulocyte colonystimulating factor (G-CSF), and C-C motif chemokine 11 (CCL11). In addition, C-reactive protein (CRP) was assessed using an R\&D Systems Solid Phase Sandwich ELISA. Samplesthat were collected from the same individual before and after swimming were analyzed in the same analytical batch. Quality control samples were run in duplicate with the study samples in each batch. Serum concentrations for IL-1 $\beta$, IL-4, IL-5, IL-6, IL-10, IL-13, IL-17, TNF- $\alpha$, MIP1 beta, CXCL1, and FGF basic were below the limits of quantification (LOQ) in more than $60 \%$ of the samples and were therefore excluded from main analyses. The remaining markers were imputed using a maximum likelihood estimation 
procedure (Lubin et al., 2004). To allow for plate to plate variation we imputed based on each platespecific limit of quantification and included plate as a predictor variable in the imputation model.

\subsection{Covariate data}

Questionnaires were used to collect information on personal and family history of atopic diseases, exposure to environmental tobacco smoke, diet, sociodemographic data, frequency and duration of swimming pool attendance and other physical activity, and way of commuting to the swimming pool facility. Weight and height were measured with standard procedures.

\subsection{Statistical analysis}

We calculated Pearson correlation coefficients to assess the correlation between quantitative markers of exposure due to swimming in a chlorinated pool, and between immune markers measured in serum. In addition we calculated intraclass correlation coefficients (ICC) for THMs in exhaled breath and immune markers in serum. We used density plots to present serum immune marker concentration distributions before and after swimming. We natural log transformed all immune marker concentrations, as distributions were skewed.

We assessed the association between indicators of swimming in a chlorinated pool and changes in serum immune marker concentrations using a bivariate normal model which estimated the mean immune marker level before swimming (intercept), the change in immune marker level due to swimming, and the residual variance covariance matrix across the two immune marker measurements per subject.

Our main model included a dichotomous indicator for swimming (pre vs. post swimming) to assess the percentage change in immune marker concentrations due to 40 minutes of swimming in a chlorinated pool. To assess the independent contribution of the quantitative exposure markers (THMs in exhaled breath and physical activity) in addition to the swimming indicator, we added these to our main model, assessed their association with immune marker concentrations, and assessed their influence on the percentage change in immune marker concentration from before to after swimming. For immune markers that were below the LOQ in more than $60 \%$ of the samples, but had at least 10 observations $\geq$ LOQ and not less than 10 observations $\leq$ LOQ we conducted logistic regression to assess the impact of 40 minutes of swimming on the odds of an observations being $\geq$ LOQ. We also fitted models without the pre / post swimming indicator, including quantitative exposure markers one by one and correcting the effect of THMs for the effect for physical activity and vice versa. Finally, we assessed the association between change in concentrations of serum immune markers and air concentrations of trichloramine at the day of swimming. We consider this 
marker a relatively poor proxy for exposure, as true internal exposure is affected by physical activity, sex, and temperature (Marco et al., 2015).

All regression analyses were adjusted for age, sex, and BMI. We adjusted for multiple comparisons by calculating for each immune marker q-values based on $p$-values reported by the regression models using the Benjamini-Hochberg procedure. We defined $q=5 e-02$ as the threshold for a significant association. 


\section{Results}

We included 30 women and 29 men with a median age of 24 years in this study. All study participants were non-smokers and none of them were professional swimmers. Further descriptive statistics and median concentrations of relevant DBPs in swimming water and in exhaled breath are reported in Table 1.

Measured swimming pool water concentrations of DBPs were comparable to levels previously observed in Europe (Chowdhury et al., 2014) and the United States (Weaver et al., 2009). Correlations between serum immune markers before and after swimming were generally low, though some markers were significantly correlated (Appendix Table A.1). CCL2 and CCL11 were the only pair of markers with a Pearson correlation $>0.50(r=0.68$ and 0.66 , before and after swimming, respectively). ICCs for serum immune markers ranged from 0.33 (EGF) to 0.99 (CRP). We observed significant correlations between the THMs measured in exhaled breath before swimming $(r>0.35)$ and these increased after swimming ( $>0.57$; Appendix Table A.2). ICCs for all THMs were close to zero. Quantitative markers of exposure to TTHM, Kcal, \%HR, and distance swum were highly correlated when calculated across pre- and post-swimming measurements ( $r>0.80$; Table 2$)$, and correlations among post-swimming measurements were generally much lower $(r 0.18-0.83$; Table 2).

We show density plots of natural log transformed serum immune marker concentrations before (continuous line) and after (dashed line) swimming in Figure 1. We observe a visual shift in the distribution of serum concentrations of IL-8, CCL22, CCL11, CRP, CXCL10, IL-1RA, and CCL2 from before to after swimming. Results from our main regression model (Table 3 ) are in line with this observation.

We observed a significant decrease in serum concentrations of IL-8 (-12.53\%; q=2.00e-03), CCL22 (7.28\%; q=4.00e-04), CCL11 (-7.15\%; q=9.48e-02), CRP (-7.06\%; q=4.68e-05), and CXCL10 (-13.03\%; $q=6.34 \mathrm{e}-14)$ and a significant increase in IL-1RA (20.16\%; $q=4.18 \mathrm{e}-06)$ from before to after swimming. When we added the quantitative estimate of TTHM measured in exhaled breath or the total distance swum to the model, the magnitude of change (adjusted for these quantitative variables) dropped for all markers and no longer met our threshold for significance. A similar effect was observed when we added Kcal or \%HR to the models, though in these models the remaining effect for CXCL10 still met our threshold for significance. Estimates for TTHM or Kcal from these models also did not meet our threshold for significance (Appendix Table A.3). Effects for men and women were in the same direction for the significantly changed serum markers. We observed a statistically significant multiplicative interaction for IL-1RA ( $p=1.52 e-02$ ) (Appendix, Table A.4). 
Effects of quantitative estimates of TTHM, distance swum, and \%HR on serum immune marker concentrations presented in Table 4 paralleled the results reported in Table 3. We observed significant negative associations between increasing exposure of the quantitative markers of swimming in a chlorinated pool and IL-8, CCL22, CCL11, CRP, CXCL10, and a significant positive association with IL-1RA. When we added quantitative estimates of \%HR and Kcal to the model that contained TTHM as the main effect, none of the significant associations remained (with the exception of a significant effect for CXCL10 in a model adjusted for \%HR). Results for TTHM adjusted for distance swum were marginally different from the analyses that were adjusted for Kcal (Pearson correlation between these two variables $r=0.97$; results not shown). None of the immune markers were associated to either Kcal or \%HR in analyses that were adjusted for TTHM. Results for individual THMs ( $\left.\mathrm{Cl}_{3} \mathrm{CH}, \mathrm{BDCM}, \mathrm{DBCM}, \mathrm{Br}_{3} \mathrm{CH}\right)$ were similar to those obtained for TTHM (Appendix, Table A.5).

We observed that a borderline significantly increased odds ratio of serum level $\geq$ LOQ after swimming for IL-6 (nominal $p$-value $=0.05$ ). Odds ratios were non-significantly above unity for TNF- $\alpha$ and below unity for CXCL1, G-CSF, and CCL11 (Appendix, Table A.6).

Reasoning that air concentrations of trichloramine can serve as a proxy for internal exposure to DBPs not affected by an effect of physical activity, we assessed the association between trichloramine in air and changes in immune marker concentrations (results in Appendix, Table A.7). We observed no significant associations between trichloramine measured in air and changes in immune marker serum concentrations. 


\section{Discussion}

We observed acute changes in seven immune markers (CCL2, CCL11, CCL22, CXCL10, CRP, IL-8, and IL-1RA) after swimming in a chlorinated pool. The observed changes were significantly associated to quantitative markers of exposure to DBPs (measured by THMs in exhaled breath) and quantitative markers of the physical activity spent during 40 minutes of exercise. No significant association remained when we adjusted the effects of exposure to DBPs for physical activity (or vice versa). We did not observe associations between air concentration of trichloramine and changes in serum immune marker concentrations.

\subsection{Biological role of the affected immune markers}

The immune markers that were affected by 40 minutes swimming in a swimming pool can be functionally divided into pro-inflammatory (Th1 associated; CXCL10, IL-8) and anti-inflammatory (Th2 associated; CCL2, CCL11, CCL22) chemokines, a pro-inflammatory cytokine inhibitor (IL-1RA), and an acute-phase protein (CRP). Chemokines are a superfamily of homologous 8-10 kDa heparin-binding proteins involved in leukocyte recruitment to sites of inflammation, but are also involved in angiogenesis in both physiological and pathological contexts (Zlotnik and Yoshie 2000). For example, CCL-2 and IL-8 are co-expressed during the initial stages of wound healing (Salcedo et al., 2000). IL1RA antagonizes the strong pro-inflammatory cytokine IL-1 by binding to the IL-1 receptor with high affinity without activating the cell. In several diseases IL-1RA is elevated, compensating for the increase in IL-1 induced by the disease process (Hurme and Santtila 1998). We observed a significant difference between men and women in the response of IL-1RA to swimming in a chlorinated pool. This is in line with previous reports of a sex specific response of IL-1RA to external triggers (Daun et al., 2000). CRP is a plasma protein that binds to specific molecular configurations found on the surface of pathogens. After an acute inflammatory stimulus, CRP levels rise rapidly as part of the acute phase response (Black et al., 2004).

CXCL10 is the immune marker that was most strongly affected in our study. It plays a role in a multitude of biological pathways including stimulation of monocytes, natural killer cells and T-cells, regulation of T-cell and bone marrow progenitor maturation, modulation of adhesion molecule expression and inhibition of angiogenesis (Zhao et al., 2012). CXCL10 is involved in chemotaxis, induction of apoptosis, and regulation of cell growth and has been reported to play a dual role in cancer by both inhibiting and stimulating cell proliferation (Liu et al., 2011). Furthermore, CXCL10 has been reported to play a role in airway hyperreactivity and airway inflammation (Medoff et al., 2002), and health outcomes that have been associated with swimming in a chlorinated pool (Villanueva et al., 2015; Villanueva and Font-Ribera, 2012). 


\subsection{Independent effects of DBPs on immune markers}

A challenge of the current study design was the strong correlation between the quantitative markers THMs in exhaled breath and quantitative markers of physical activity. The correlation is explained by the large role that physical activity plays in the total internal exposure to THMs that is received due to swimming in a chlorinated pool (Marco et al., 2015). Due to the strong correlations that were observed between air concentrations of THMs (not available in this study), physical activity, and THMs measured in exhaled breath, inhalation has been suggested as the primary mechanism of THM uptake (Marco et al., 2015). The strong correlation between these quantitative markers makes that with our study design it was not possible to attribute the effect to either exposure to DBPs or to physical activity. Even though it has a different composition of DPBs (and in much lower concentrations), literature on the effect of chlorinated drinking water (no confounding by physical activity) and exercise (no confounding by exposure to DBPs) does provide some insight into the independent effects of these factors on the affected immune markers.

Evidence from a handful of animal studies points towards an immunosuppressive effect of DBPs in drinking water. Munson et al. (1982) reported immunosuppression in mice after administration of BDCM or DBCM ; Exon et al. (1987) reported immunosuppression in rats after high doses to chlorinebased disinfectants, Ueno et al. (1999) reported suppression of immune responses in mice after exposure to chlorinated humic acid-concentrate as a mixture of chlorination by-products, and Auttachoat et al. (2009) observed a decreased number of circulating neutrophils in blood of mice exposed to chloroform, though neutrophil function in lung homogenates was not compromised. French et al. (1999) found no effects of BDCM on the immune function of mice and rats after exposure through drinking water and oral gavage.

Further evidence for immunosuppressive effects of DBPs comes from studies of halocarbons that are structurally very similar to DBPs. Trichloroethylene differs from chloroform by the presence of an additional carbon atom and a carbon-carbon double bond, while one of the major metabolites of TCE is trichloroacetaldehyde (TCAA), a DBP. Increased serum levels of interferon-gamma and decreased levels of IL-4 were observed in mice exposed to trichloroethylene (Griffin et al., 2000). Occupational exposure to trichloroethylene has been associated with elevated serum levels of interferon-gamma and IL-2 and decreased levels of IL-4 and IL-10 (no effect on IL-6 or tumor necrosis factor (TNF)-alpha was observed) (Bassig et al., 2013; lavicoli et al., 2005). Tetrachloride is another haloalkane similar to chloroform for which mechanistic studies have demonstrated an effect on the production of TNFalpha, transforming growth factors (TGF)-alpha and beta, IL-6, and IL-10 (Weber et al., 2003).

\subsection{Independent effect of physical activity on immune markers}


Short-term, transient increases in serum CRP, IL-1RA, and IL-8 after strenuous exercise due to an exercise-induced acute phase response) have been reported consistently in the literature (Kasapis and Thompson 2005). Importantly, the majority of these studies were conducted among trained athletes that are known to experience a decrease in several immune markers resulting from prolonged (long-term) exercise. In our study the effect for IL-1RA was in the same direction as the effect observed for physical activity, but the effects for CRP and IL-8 were in the opposite direction. We did observe a significantly elevated odds ratio for detection after swimming for IL-6 (indicating IL6 levels increased from before to after swimming), which is a potent inducer of IL-1RA and has been reported to increase after physical activity (Ostrowski et al., 2000; Steensberg et al., 2003). We did not identify any studies among healthy individuals reporting on the effects of exercise on the other immune markers included in our study.

\subsection{Using peripheral blood to assess changes in immune markers}

While our rate of detection for some immune markers was low, for most of the immune markers that we did successfully detect, we observed strong associations with swimming in a chlorinated pool. This is in contrast with previous studies in chlorinated swimming pools that used exhaled breath condensate collected one hour after swimming (in contrast to two hours after swimming in our current study) to measure immune markers (and in which high detection rates were reported) (FontRibera et al., 2010; Pedersen et al., 2009). Blood sampling is also much less labor intensive than collection of exhaled breath condensate. We therefore suggest serum as a suitable and sensitive biological matrix for sampling immune markers in future studies of the effects of swimming in chlorinated pools.

\subsection{Disentangling the effect of exposure to DBPs on immune markers from physical activity}

In the current analysis we were not able to statistically distinguish the effect of exposure to DBPs on immune marker levels from the effect of physical activity on immune marker levels. Future studies should focus on designs that decrease the correlations between THMs measured in exhaled breath and physical activity. A recent example of such a design was provided by Llana-Belloch et al. (2016). In this study three pools with different characteristics and different methods for water disinfection were included in a cross-over design.

\subsection{Conclusion}

In this study we observed strong acute changes in seven immune markers (CCL2, CCL11, CCL22, CXCL10, CRP, IL-8, and IL-1RA) after swimming in a chlorinated pool. With our study design, it was not possible to attribute this effect to either exposure to DBPs (measured by THMs in exhaled breath) or 
to physical activity. Reviewing the literature we observed evidence for an immune response due to physical activity and evidence for immunosuppression due to exposure to DBPs. This provides support that the decrease in immune markers concentrations we observed for most significantly associated markers is more likely attributable to exposure to DBPs rather than to physical activity, though the effect of other (unmeasured) influences on these immune markers cannot be fully excluded.

Acknowledgements: This work was supported by the grant FP7 of the European Commission 'Enhanced exposure assessment and omic profiling for high priority environmental exposures in Europe' (no. 308610). 


\section{References}

Ainsworth, B.E., Haskell, W.L., Whitt, M.C., Irwin, M.L., Swartz, A.M., Strath, S.J., et al., 2000. Compendium of physical activities: an update of activity codes and MET intensities. Med. Sci. Sports Exerc. 32, S498-504.

Auttachoat, W., Germolec, D.R., Collins, B.J., Luebke, R.W., White, K.L., Guo, T.L., 2009. Immunotoxicological profile of chloroform in female B6C3F1 mice when administered in drinking water. Drug Chem. Toxicol. 32, 77-87.

Bassig, B.A., Zhang, L., Tang, X., Vermeulen, R., Shen, M., Smith, M.T., et al., 2013. Occupational exposure to trichloroethylene and serum concentrations of IL-6, IL-10, and TNF-alpha. Environ. Mol. Mutagen. 54, 450-454.

Black, S., Kushner, I., Samols, D., 2004. C-reactive Protein. J. Biol. Chem. 279, 48487-48490.

Chowdhury, S., Alhooshani, K., Karanfil, T., 2014. Disinfection byproducts in swimming pool: occurrences, implications and future needs. Water Res. 53, 68-109.

Daun, J.M., Ball, R.W., Cannon, J.G., 2000. Glucocorticoid sensitivity of interleukin-1 agonist and antagonist secretion: the effects of age and gender. Am. J. Physiol. Regul. Integr. Comp. Physiol. 278, R855-862.

Exon, J.H., Koller, L.D., O'Reilly, C.A., Bercz, J.P., 1987. Immunotoxicologic evaluation of chlorinebased drinking water disinfectants, sodium hypochlorite and monochloramine. Toxicology 44, 257-269.

Font-Ribera, L., Kogevinas, M., Schmalz, C., Zwiener, C., Marco, E., Grimalt, J.O., et al., 2016. Environmental and personal determinants of the uptake of disinfection by-products during swimming. Environ. Res. 149, 206-215.

Font-Ribera, L., Kogevinas, M., Zock, J.-P., Gómez, F.P., Barreiro, E., Nieuwenhuijsen, M.J., et al., 2010. Short-term changes in respiratory biomarkers after swimming in a chlorinated pool. Environ. Health Perspect. 118, 1538-1544.

French, A.S., Copeland, C.B., Andrews, D., Wiliams, W.C., Riddle, M.M., Luebke, R.W., 1999. Evaluation of the potential immunotoxicity of bromodichloromethane in rats and mice. J. Toxicol. Environ. Health. A 56, 297-310.

Gleeson, M., Bishop, N.C., Stensel, D.J., Lindley, M.R., Mastana, S.S., Nimmo, M.A., 2011. The antiinflammatory effects of exercise: mechanisms and implications for the prevention and treatment of disease. Nat. Rev. Immunol. 11, 607-615.

Griffin, J.M., Blossom, S.J., Jackson, S.K., Gilbert, K.M., Pumford, N.R., 2000. Trichloroethylene accelerates an autoimmune response by Th1 $\mathrm{T}$ cell activation in $\mathrm{MRL}+/+$ mice. Immunopharmacology 46, 123-137.

Gulati, M., Shaw, L.J., Thisted, R.A., Black, H.R., Bairey Merz, C.N., Arnsdorf, M.F., 2010. Heart rate response to exercise stress testing in asymptomatic women: the st. James women take heart project. Circulation 122, 130-137.

Hurme, M., Santtila, S., 1998. IL-1 receptor antagonist (IL-1Ra) plasma levels are co-ordinately regulated by both IL-1Ra and IL-1beta genes. Eur. J. Immunol. 28, 2598-2602.

lavicoli, I., Marinaccio, A., Carelli, G., 2005. Effects of occupational trichloroethylene exposure on 
cytokine levels in workers. J. Occup. Environ. Med. 47, 453-457.

Jacobs, J.H., Spaan, S., van Rooy, G.B.G.J., Meliefste, C., Zaat, V.A.C., Rooyackers, J.M., et al., 2007. Exposure to trichloramine and respiratory symptoms in indoor swimming pool workers. Eur. Respir. J. 29.

Kasapis, C., Thompson, P.D., 2005. The effects of physical activity on serum C-reactive protein and inflammatory markers: a systematic review. J. Am. Coll. Cardiol. 45, 1563-1569.

Llana-Belloch, S., Priego Quesada, J.I., Pérez-Soriano, P., Lucas-Cuevas, Á.G., Salvador-Pascual, A., Olaso-González, G., et al., 2016. Disinfection by-products effect on swimmers oxidative stress and respiratory damage. Eur. J. Sport Sci. 16, 609-617.

Liu, M.,, Guo, S.,, Stiles, J.K., JK. 2011. The emerging role of CXCL10 in cancer (Review). Oncol. Lett. 2, 583-589.

Lubin, J.H., Colt, J.S., Camann, D., Davis, S., Cerhan, J.R., Severson, R.K., et al., 2004. Epidemiologic evaluation of measurement data in the presence of detection limits. Environ. Health Perspect. $112,1691-1696$.

Marco, E., Lourencetti, C., Grimalt, J.O., Gari, M., Fernández, P., Font-Ribera, L., et al., 2015. Influence of physical activity in the intake of trihalomethanes in indoor swimming pools. Environ. Res. $140,292-299$.

Medoff, B.D., BD, Sauty, A.,, Tager, A.M., AM, Maclean, J.A., JA, Smith, R.N., RN, Mathew, A.,, et al.,. 2002. IFN- -inducible proteinInducible Protein 10 (CXCL10) contributesContributes to airway hyperreactivityAirway Hyperreactivity and airway inflammationAirway Inflammation in a mouse modelMouse Model of Asthma. J. Immunol. 168, 5278-5286.

Munson, A.E., Sain, L.E., Sanders, V.M., Kauffmann, B.M., White, K.L., Page, D.G., et al., 1982. Toxicology of organic drinking water contaminants: trichloromethane, bromodichloromethane, dibromochloromethane and tribromomethane. Environ. Health Perspect. 46, 117-126.

Ostrowski, K., Schjerling, P., Pedersen, B.K., 2000. Physical activity and plasma interleukin-6 in humans--effect of intensity of exercise. Eur. J. Appl. Physiol. 83, 512-515.

Pedersen, L., Lund, T.K., Mølgaard, E., Kharitonov, S.A., Barnes, P.J., Backer, V., 2009. The acute effect of swimming on airway inflammation in adolescent elite swimmers. J. Allergy Clin. Immunol. $123,502-504$.

Salcedo, R., Ponce, M.L., Young, H.A., Wasserman, K., Ward, J.M., Kleinman, H.K., et al., 2000. Human endothelial cells express CCR2 and respond to MCP-1: direct role of MCP-1 in angiogenesis and tumor progression. Blood 96, 34-40.

Steensberg, A., Fischer, C.P., Keller, C., Møller, K., Pedersen, B.K., 2003. IL-6 enhances plasma IL-1ra, IL-10, and cortisol in humans. Am. J. Physiol. Endocrinol. Metab. 285, E433-437.

Ueno, H., Oishi, K., Kubota, T., Sayato, Y., 1999. Effects of Chlorination By-products on Immune Response (PROCEEDINGS OF 24TH SYMPOSIUM ON TOXICOLOGY AND ENVIRONMENTAL HEALTH). J. Heal.

Villanueva, C.M., Cordier, S., Font-Ribera, L., Salas, L.A., Levallois, P., 2015. Overview of disinfection by-products and associated health effects. Curr. Environ. Heal. reports 2, 107-115.

Villanueva, C.M., Font-Ribera, L., 2012. Health impact of disinfection by-products in swimming pools. 
Ann. Ist. Super. Sanita 48, 387-396.

Weaver, W.A., Li, J., Wen, Y., Johnston, J., Blatchley, M.R., Blatchley, E.R., 2009. Volatile disinfection by-product analysis from chlorinated indoor swimming pools. Water Res. 43, 3308-3318.

Weber, L.W.D., Boll, M., Stampfl, A., 2003. Hepatotoxicity and mechanism of action of haloalkanes: carbon tetrachloride as a toxicological model. Crit. Rev. Toxicol. 33, 105-136.

Zhao, X.,, Gou, M.,, Deng, H.,, Yi, T.,, Zhong, Q.,, Wei, Y.,, et al.,. 2012. Efficient inhibition of ovarian cancer by recombinant CXC chemokine ligand 10 delivered by novel biodegradable cationic heparin-polyethyleneimine nanogels. Oncol. Rep. 28, 668-67676.

Zlotnik, A., Yoshie, O., 2000. Chemokines: a new classification system and their role in immunity. Immunity $12,121-127$. 
Table 1. Descriptive statistics for anthropometric characteristics, exposure to disinfection byproducts, and physical activity of the study population

\begin{tabular}{|c|c|}
\hline Measurement (unit) & $\mathrm{N}$ or median (range) \\
\hline individuals $(\mathrm{N})$ & 30 women and 29 men \\
\hline Age (yr) & $24(18-38)$ \\
\hline $\mathrm{BMl}^{\mathrm{a}}\left(\mathrm{kg} / \mathrm{m}^{2}\right)$ & $23.2(16.6-32.5)$ \\
\hline Distance swum (m) & $1050(200-1850)$ \\
\hline Energy expenditure ${ }^{\mathrm{b}}$ (Kcal) & $197.8(58.3-417.3)$ \\
\hline $\begin{array}{l}\text { Percentage heart rate values indicating high } \\
\text { intensity physical activityc }(\%)\end{array}$ & $70.3(0.0-99.1)$ \\
\hline Concentration trichloramine in air $\left(\mu \mathrm{g} / \mathrm{m}^{3}\right)$ & $472.0(248.5-858.3)$ \\
\hline Concentration DBPs ${ }^{d}$ in swimming water $(\mu \mathrm{g} / \mathrm{L})$ & $\begin{array}{l}\mathrm{CHCl}_{3} 35.8 \text { (25.4-60.6); } \\
\mathrm{BDCM} 7.3(3.8-12.9) ; \mathrm{DBCM} 2.5(1.1-4.7) ;\end{array}$ \\
\hline $\begin{array}{l}\text { Concentration TTHMs }{ }^{d} \text { in exhaled breath after } \\
\text { swimming }\left(\mu \mathrm{g} / \mathrm{m}^{3}\right)\end{array}$ & $\begin{array}{l}\mathrm{Br}_{3} \mathrm{CH} 0.9(0.2-1.9) ; \\
\mathrm{Cl}_{3} \mathrm{CH} 11.7(2.7-26.3) ; \mathrm{BDCM} 2.2(0.4-6.4) ; \\
\text { DBCM } 0.5(0.1-1.7) ; \mathrm{Br}_{3} \mathrm{CH} 0.1(0.0-0.4) ; \\
\text { TTHM } 14.5 \text { (3.3-32.6). }\end{array}$ \\
\hline
\end{tabular}

\footnotetext{
${ }^{a}$ Body Mass Index

${ }^{\mathrm{b}}$ Kcal $=$ weight $(\mathrm{kg}) \times \frac{\text { distance swaum }(\mathrm{m})}{\text { minute }} \times$ swimming duration $(\mathrm{hr}) \times 8.3\left(\frac{\mathrm{kcal} / \mathrm{kg}}{\mathrm{hr}}\right) / 46(\mathrm{~m} / \mathrm{min})$

${ }^{\mathrm{C}}$ Change in the percentage of monitored heart rate values during swimming that was higher than 69 percent of the individual maximum heart rate (indicating high intensity physical activity).

${ }^{d}$ Chloroform $\left(\mathrm{CHCl}_{3}\right)$, bromodichloromethane (BDCM), dibromochloromethane (DBCM), bromoform $\left(\mathrm{Br}_{3} \mathrm{CH}\right)$, total trihalomethanes (TTHM).
} 
Table 2. Pearson correlation coefficients for quantitative markers of exposure due to swimming in a chlorinated pool ${ }^{a}$. Significantly correlated markers (q value $<0.05$ ) were bolded.

\begin{tabular}{l|llll}
\multicolumn{1}{c}{} & TTHM $^{\mathrm{b}}$ & Distance $^{\mathrm{c}}$ & Kcal $^{\mathrm{d}}$ & \%HR $^{\mathrm{e}}$ \\
\cline { 2 - 5 } TTHM $^{\mathrm{b}}$ & & 0.30 & $\mathbf{0 . 2 9}$ & $\mathbf{0 . 2 7}$ \\
Distance $^{\mathrm{c}}$ & $\mathbf{0 . 8 5}$ & & $\mathbf{0 . 8 3}$ & 0.25 \\
Kcal $^{\mathrm{d}}$ & $\mathbf{0 . 8 3}$ & $\mathbf{0 . 9 7}$ & & 0.18 \\
\%HR $^{\mathrm{e}}$ & $\mathbf{0 . 8 0}$ & $\mathbf{0 . 8 2}$ & $\mathbf{0 . 8 0}$ &
\end{tabular}

${ }^{a}$ The lower triangular part of the matrix contains correlation coefficients between markers when pre- and postswimming measurements are combined in one dataset. The upper triangular part of the matrix contains correlation coefficients between the markers measured post-swimming.

${ }^{b}$ Change in total trihalomethanes (TTHM) measured in exhaled breath.

${ }^{\mathrm{c}}$ Distance swum (meters).

${ }^{d}$ Change in energy expenditure (kilocalories).

${ }^{\mathrm{e}}$ Change in the percentage of monitored heart rate values while swimming that was higher than 69 percent of the individual maximum heart rate (indicating high intensity physical activity). 
Table 3. Percentage difference in serum immune marker concentrations before and after swimming in a chlorinated pool.

\begin{tabular}{|c|c|c|c|c|c|}
\hline $\begin{array}{l}\text { Immune } \\
\text { marker }\end{array}$ & $\%$ change $^{a}$ & $\begin{array}{l}\% \text { change }^{a} \\
\text { adjusted for } \\
\text { TTHM }^{b}\end{array}$ & $\begin{array}{l}\% \text { change }^{\mathrm{a}} \\
\text { adjusted for }^{\mathrm{c}} \\
\text { Kcal }^{\mathrm{c}}\end{array}$ & $\begin{array}{l}\% \text { change }^{a} \\
\text { adjusted for } \\
\%_{H R^{d}}\end{array}$ & $\begin{array}{l}\% \text { change }^{a} \\
\text { adjusted for } \\
\text { distance }^{\mathrm{e}}\end{array}$ \\
\hline CCL11 & $\begin{array}{l}-7.15 \% \\
(q=9.48 e-02)\end{array}$ & $\begin{array}{l}-1.8 \% \\
(q=8.32 \mathrm{e}-01)\end{array}$ & $\begin{array}{l}-7.33 \% \\
(q=6.59 e-01)\end{array}$ & $\begin{array}{l}4.95 \% \\
(q=8.60 e-01)\end{array}$ & $\begin{array}{l}-4.60 \% \\
(q=7.74 \mathrm{e}-01)\end{array}$ \\
\hline CCL2 & $\begin{array}{l}-6.29 \% \\
(q=9.48 e-02)\end{array}$ & $\begin{array}{l}-11.6 \% \\
(q=3.94 e-01)\end{array}$ & $\begin{array}{l}-9.76 \% \\
(q=4.97 e-01)\end{array}$ & $\begin{array}{l}-3.86 \% \\
(q=8.79 e-01)\end{array}$ & $\begin{array}{l}-4.50 \% \\
(q=7.74 \mathrm{e}-01)\end{array}$ \\
\hline CCL22 & $\begin{array}{l}-7.28 \% \\
(q=4.00 \mathrm{e}-04)\end{array}$ & $\begin{array}{l}-3.3 \% \\
(q=8.03 e-01)\end{array}$ & $\begin{array}{l}0.03 \% \\
(q=9.96 e-01)\end{array}$ & $\begin{array}{l}-1.14 \% \\
(q=9.23 e-01)\end{array}$ & $\begin{array}{l}8.15 \% \\
(q=4.11 e-01)\end{array}$ \\
\hline CRP & $\begin{array}{l}-7.06 \% \\
(q=4.68 e-05)\end{array}$ & $\begin{array}{l}-6.6 \% \\
(q=3.94 e-01)\end{array}$ & $\begin{array}{l}-9.11 \% \\
(q=2.80 e-01)\end{array}$ & $\begin{array}{l}-7.81 \% \\
(q=2.59 e-01)\end{array}$ & $\begin{array}{l}-9.63 \% \\
(q=1.84 e-01)\end{array}$ \\
\hline CXCL10 & $\begin{array}{l}-13.03 \% \\
(q=6.34 e-14)\end{array}$ & $\begin{array}{l}-10.4 \% \\
(q=7.12 e-02)\end{array}$ & $\begin{array}{l}-15.66 \% \\
(q=2.90 e-03)\end{array}$ & $\begin{array}{l}-16.33 \% \\
(q=6.21 e-05)\end{array}$ & $\begin{array}{l}-15.56 \% \\
(q=1.35 e-02)\end{array}$ \\
\hline EGF & $\begin{array}{l}-20.76 \% \\
(q=1.63 e-01)\end{array}$ & $\begin{array}{l}-52.3 \% \\
(q=1.56 e-01)\end{array}$ & $\begin{array}{l}-34.61 \% \\
(q=4.97 e-01)\end{array}$ & $\begin{array}{l}-10.15 \% \\
(q=9.23 e-01)\end{array}$ & $\begin{array}{l}-23.35 \% \\
(q=7.69 e-01)\end{array}$ \\
\hline G-CSF & $\begin{array}{l}-0.74 \% \\
(q=9.38 e-01)\end{array}$ & $\begin{array}{l}-4.7 \% \\
(q=8.32 e-01)\end{array}$ & $\begin{array}{l}-24.61 \% \\
(q=4.97 e-01)\end{array}$ & $\begin{array}{l}-2.63 \% \\
(q=9.23 e-01)\end{array}$ & $\begin{array}{l}-24.40 \% \\
(q=5.31 e-01)\end{array}$ \\
\hline IL-17 & $\begin{array}{l}2.67 \% \\
(q=8.84 e-01)\end{array}$ & $\begin{array}{l}23.1 \% \\
(q=5.45 e-01)\end{array}$ & $\begin{array}{l}11.98 \% \\
(q=6.59 e-01)\end{array}$ & $\begin{array}{l}12.94 \% \\
(q=8.60 e-01)\end{array}$ & $\begin{array}{l}34.92 \% \\
(q=4.01 e-01)\end{array}$ \\
\hline IL-1RA & $\begin{array}{l}20.16 \% \\
(q=4.18 e-06)\end{array}$ & $\begin{array}{l}1.8 \% \\
(q=8.32 e-01)\end{array}$ & $\begin{array}{l}19.37 \% \\
(q=3.03 e-01)\end{array}$ & $\begin{array}{l}10.05 \% \\
(q=7.43 e-01)\end{array}$ & $\begin{array}{l}31.59 \% \\
(q=7.13 e-02)\end{array}$ \\
\hline IL-8 & $\begin{array}{l}-12.53 \% \\
(q=2.00 e-03)\end{array}$ & $\begin{array}{l}-7.1 \% \\
(q=8.03 e-01)\end{array}$ & $\begin{array}{l}-1.93 \% \\
(q=9.28 e-01)\end{array}$ & $\begin{array}{l}-9.35 \% \\
(q=7.43 e-01)\end{array}$ & $\begin{array}{l}-2.30 \% \\
(q=9.18 \mathrm{e}-01)\end{array}$ \\
\hline MPO & $\begin{array}{l}-3.49 \% \\
(q=8.77 e-01)\end{array}$ & $\begin{array}{l}-21.8 \% \\
(q=5.45 e-01)\end{array}$ & $\begin{array}{l}-16.32 \% \\
(q=6.59 e-01)\end{array}$ & $\begin{array}{l}16.72 \% \\
(q=8.60 e-01)\end{array}$ & $\begin{array}{l}0.45 \% \\
(q=9.87 e-01)\end{array}$ \\
\hline Periostin & $\begin{array}{l}1.21 \% \\
(q=3.05 e-01)\end{array}$ & $\begin{array}{l}1.1 \% \\
(q=8.32 e-01)\end{array}$ & $\begin{array}{l}1.74 \% \\
(q=6.59 e-01)\end{array}$ & $\begin{array}{l}-0.23 \% \\
(q=9.23 e-01)\end{array}$ & $\begin{array}{l}2.14 \% \\
(q=7.69 e-01)\end{array}$ \\
\hline VEGF & $\begin{array}{l}1.20 \% \\
(q=9.38 e-01)\end{array}$ & $\begin{array}{l}11.7 \% \\
(q=8.32 e-01)\end{array}$ & $\begin{array}{l}47.98 \% \\
(q=3.03 e-01)\end{array}$ & $\begin{array}{l}31.34 \% \\
(q=7.26 e-01)\end{array}$ & $\begin{array}{l}90.38 \% \\
(q=7.13 e-02)\end{array}$ \\
\hline
\end{tabular}

${ }^{a}$ Percentage change in serum immune markers concentration determined before and after swimming in a chlorinated pool, adjusted for sex, age, and BMI. Serum concentrations were log-transformed in the regression model. $q$-values were based on $\mathrm{p}$ values reported by the regression models using the Benjamini-Hochberg procedure.

${ }^{\mathrm{b}}$ Additionally adjusted for change in total trihalomethanes (TTHM) measured in exhaled breath.

${ }^{c}$ Additionally adjusted for change in energy expenditure (kilocalories).

${ }^{d}$ Additionally adjusted for change in the percentage of monitored heart rate values while swimming that was higher than 69 percent of the individual maximum heart rate (indicating high intensity physical activity).

${ }^{\mathrm{e}}$ Additionally adjusted for distance swum (meters). 
Table 4. Association between quantitative markers of exposure due to swimming in a chlorinated pool and absolute change in concentration of serum immune markers ${ }^{a}$.

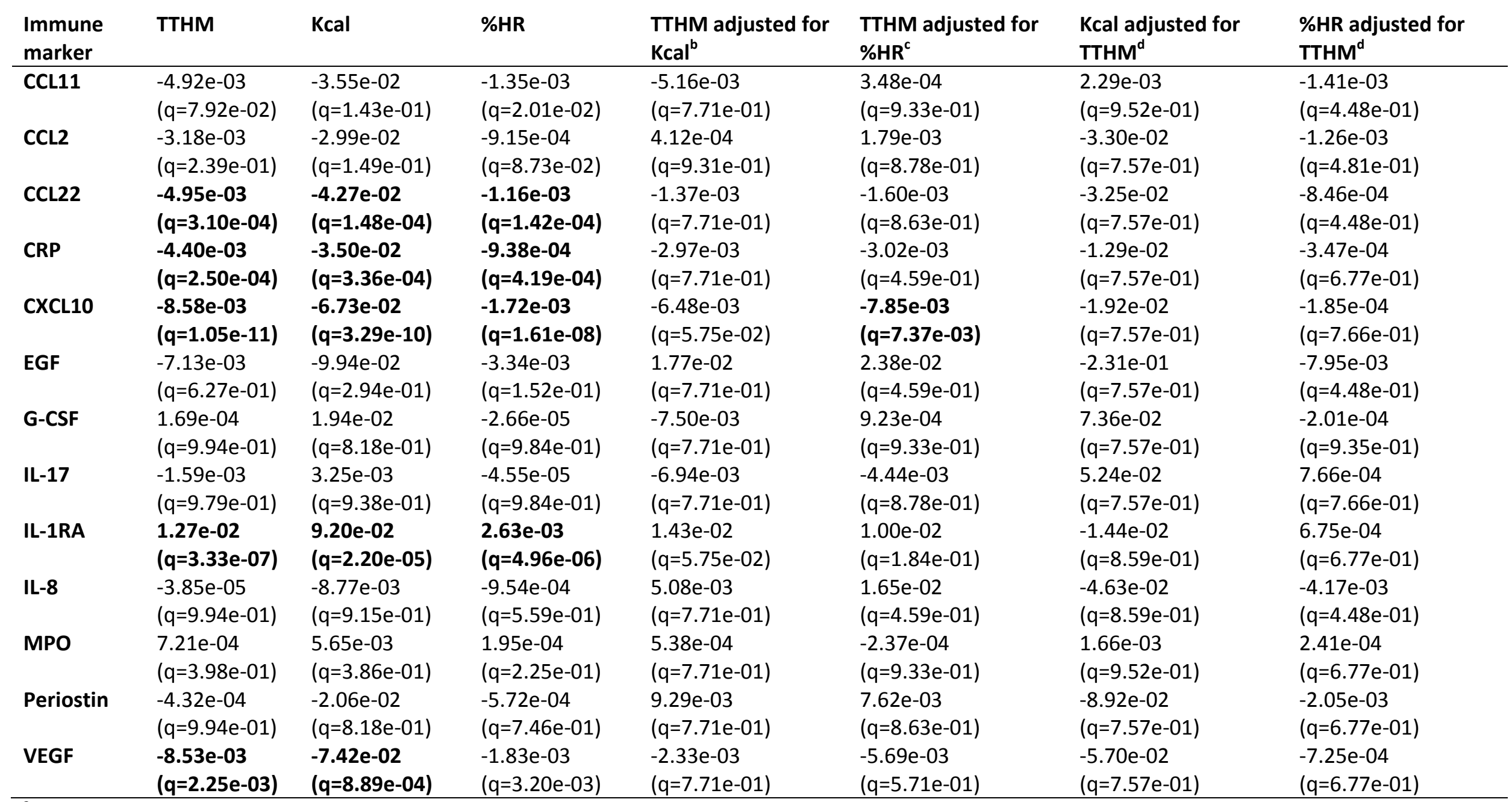

${ }^{a}$ Change in serum immune markers concentration determined before and after swimming in a chlorinated pool, adjusted for sex, age, and BMI. Serum concentrations were log-transformed in the regression model. q-values were based on $\mathrm{p}$ values reported by the regression models using the Benjamini- Hochberg procedure. 
${ }^{\mathrm{b}}$ Analyses additionally adjusted for change in energy expenditure (Kcal; kilocalories).

${ }^{c}$ Analyses additionally adjusted for change in the percentage of monitored heart rate values while swimming that was higher than 69 percent of the individual maximum heart rate, indicating high intensity physical activity (\%HR).

${ }^{d}$ Analyses additionally adjusted for change in total trihalomethanes (TTHM) measured in exhaled breath. 
IL-8

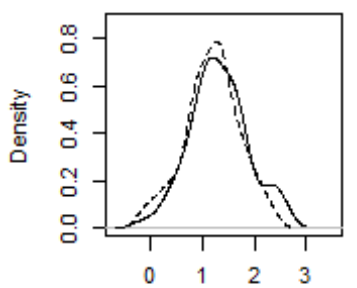

Ln marker concentration ( $\mathrm{pg} / \mathrm{ml}$ )

IL-17

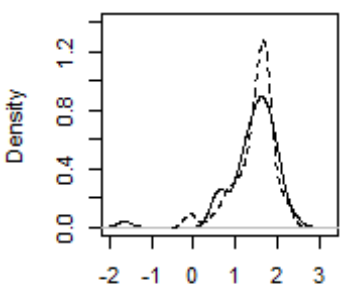

Ln marker concentration (pg/ml)
EGF

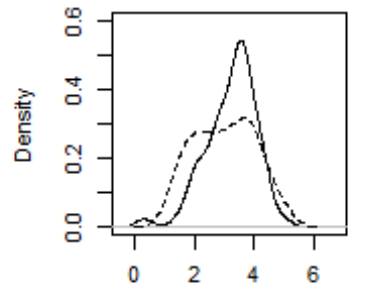

Ln marker concentration (pg/ml)

CCL22

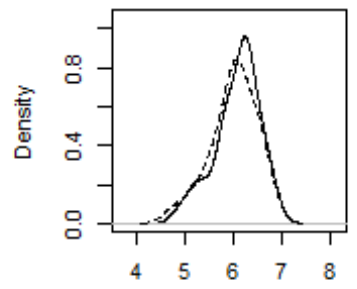

Ln marker concentration (pg/ml)
MPO

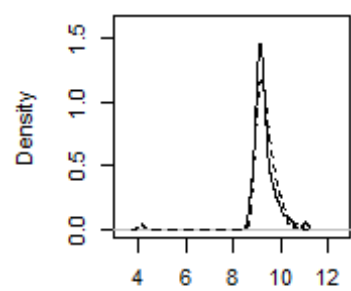

Ln marker concentration (pg/ml)

G-CSF

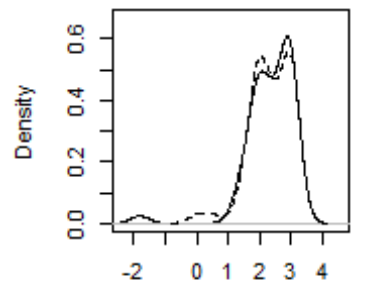

Ln marker concentration (pg/ml)
VEGF

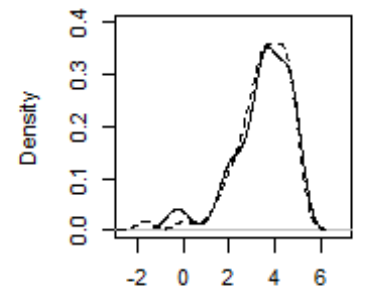

Ln marker concentration ( $\mathrm{pg} / \mathrm{ml}$ )

CCL11

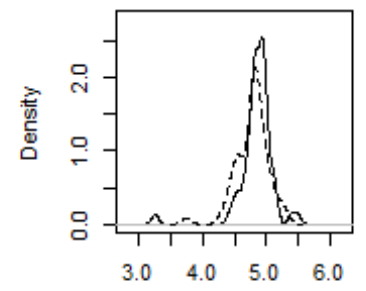

Ln marker concentration (pg/ml)

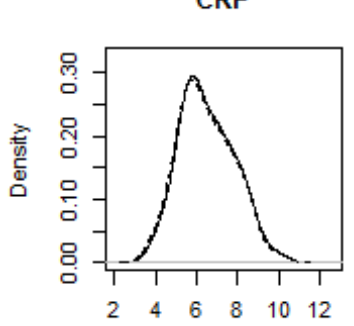

CXCL10

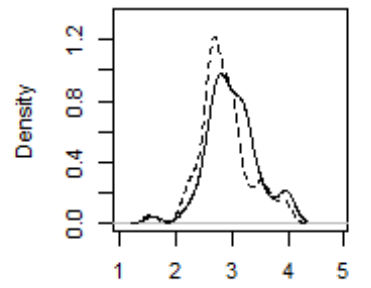

Ln marker concentration (pg/ml)

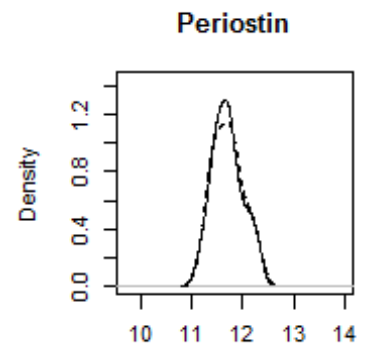

Ln marker concentration ( $\mathrm{pg} / \mathrm{ml}$ )

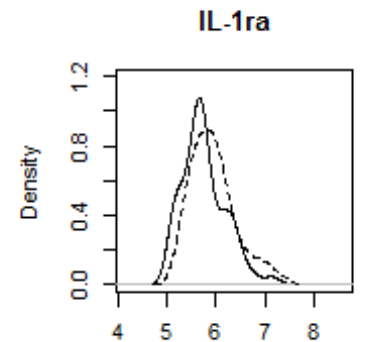

Ln marker concentration (pg/ml)

CCL2

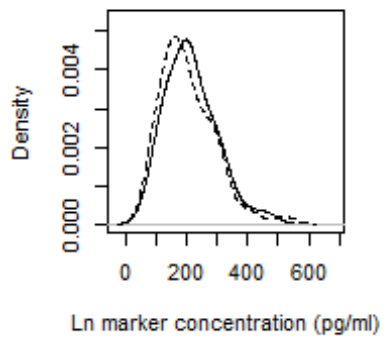

Figure 1 Density plots of natural log (In) transformed serum immune marker concentrations before (continuous line) and after (dashed line) swimming. 


\section{Appendix}

Table A.1. Matrix of Pearson correlation coefficients between immune markers measured before (below diagonal) and after (above diagonal) swimming. Significantly correlated markers (q value $<0.05$ ) were bolded.

\begin{tabular}{|c|c|c|c|c|c|c|c|c|c|c|c|c|c|}
\hline & CCL11 & CCL2 & CCL22 & CRP & CXCL10 & EGF & G-CSF & IL-17 & IL-1RA & IL-8 & MPO & Periostin & VEGF \\
\hline CCL11 & & 0.66 & 0.06 & -0.22 & 0.17 & 0.21 & 0 & -0.15 & 0.08 & 0.09 & -0.22 & 0.11 & 0.07 \\
\hline CCL2 & 0.68 & & 0.27 & -0.21 & 0.36 & 0.18 & 0 & -0.1 & 0.36 & 0.21 & -0.23 & 0.09 & 0.2 \\
\hline CCL22 & 0.16 & 0.28 & & 0.14 & 0.31 & -0.06 & 0.11 & 0.2 & 0.36 & 0.35 & -0.15 & 0.03 & 0.25 \\
\hline CRP & -0.19 & -0.15 & 0.17 & & 0.14 & -0.1 & 0.31 & 0.04 & 0.13 & 0.19 & 0 & -0.07 & 0.13 \\
\hline CXCL10 & 0.33 & 0.4 & 0.3 & 0.07 & & -0.19 & -0.17 & 0.04 & 0.19 & 0.16 & -0.06 & 0.1 & 0.06 \\
\hline EGF & 0.03 & 0.31 & 0.12 & -0.14 & 0.15 & & 0.17 & -0.02 & 0.26 & -0.06 & -0.16 & 0.28 & 0.18 \\
\hline G-CSF & 0.14 & 0.19 & 0.15 & 0.21 & -0.17 & 0.16 & & -0.09 & 0.12 & 0.16 & -0.19 & 0.3 & 0.12 \\
\hline IL-17 & 0.03 & 0.07 & 0 & -0.07 & 0.16 & 0.07 & -0.26 & & 0.03 & 0.27 & 0.26 & -0.11 & 0.12 \\
\hline IL-1RA & 0.14 & 0.34 & 0.41 & 0.33 & 0.41 & 0.04 & 0.2 & -0.02 & & 0.14 & -0.11 & -0.03 & 0.46 \\
\hline IL-8 & 0.01 & 0.1 & 0.28 & 0.24 & 0.16 & 0.17 & 0.17 & 0.11 & 0.32 & & -0.13 & -0.02 & 0.25 \\
\hline MPO & -0.11 & -0.34 & -0.11 & -0.06 & -0.08 & 0.06 & -0.3 & 0.27 & -0.26 & -0.04 & & -0.39 & 0.15 \\
\hline Periostin & 0.17 & 0.22 & 0.01 & -0.08 & 0.16 & 0.2 & 0.16 & -0.13 & -0.01 & -0.01 & -0.32 & & -0.09 \\
\hline VEGF & 0.07 & 0.11 & 0.29 & 0.1 & 0.05 & 0.04 & 0.03 & 0.13 & 0.32 & 0.25 & 0.14 & -0.04 & \\
\hline
\end{tabular}


Table A.2. Matrix of Pearson correlation coefficients between trihalomethanes in exhaled breath before (below diagonal) and after (above diagonal) swimming. Significantly correlated markers (q value $<0.05$ ) were bolded.

\begin{tabular}{r|rrrrr} 
& $\mathrm{Cl}_{3} \mathrm{CH}^{\mathrm{a}}$ & $\mathrm{BDCM}^{\mathrm{b}}$ & $\mathrm{DBCM}^{\mathrm{c}}$ & $\mathrm{Br}_{3} \mathrm{CH}^{\mathrm{d}}$ & $\mathrm{TTHM}^{\mathrm{e}}$ \\
\hline $\mathrm{Cl}_{3} \mathrm{CH}^{\mathrm{a}}$ & & 0.82 & 0.67 & 0.57 & 0.99 \\
$\mathrm{BDCM}^{\mathrm{b}}$ & 0.69 & & 0.96 & 0.84 & 0.90 \\
$\mathrm{DBCM}^{\mathrm{c}}$ & 0.40 & 0.84 & & 0.94 & 0.78 \\
$\mathrm{Br}_{3} \mathrm{CH}^{\mathrm{d}}$ & 0.35 & 0.74 & 0.88 & & 0.67 \\
$\mathrm{TTHM}^{\mathrm{e}}$ & 0.98 & 0.82 & 0.58 & 0.52 &
\end{tabular}

${ }^{\text {a }}$ Chloroform.

${ }^{\mathrm{b}}$ Bromodichloromethane.

C Dibromochloromethane.

${ }^{\mathrm{d}}$ Bromoform.

${ }^{\mathrm{e}}$ Total trihalomethanes. 
Table A.3. Association between DBPs measured in exhaled breath and physical activity and absolute change in concentration of serum immune markers, adjusted for an indicator of swimming in a chlorinated pool (before swimming vs. after swimming) ${ }^{a}$.

\begin{tabular}{lll}
$\begin{array}{l}\text { Immune } \\
\text { marker }\end{array}$ & TTHM $^{\text {b }}$ & Kcal $^{\mathbf{c}}$ \\
\hline CCL11 & $-3.91 \mathrm{e}-03$ & $1.10 \mathrm{e}-03$ \\
& $(\mathrm{q}=6.98 \mathrm{e}-01)$ & $(\mathrm{q}=9.81 \mathrm{e}-01)$ \\
CCL2 & $4.14 \mathrm{e}-03$ & $2.13 \mathrm{e}-02$ \\
& $(\mathrm{q}=6.98 \mathrm{e}-01)$ & $(\mathrm{q}=8.59 \mathrm{e}-01)$ \\
CCL22 & $-2.98 \mathrm{e}-03$ & $-4.29 \mathrm{e}-02$ \\
& $(\mathrm{q}=6.98 \mathrm{e}-01)$ & $(\mathrm{q}=8.41 \mathrm{e}-01)$ \\
CRP & $-3.25 \mathrm{e}-04$ & $1.26 \mathrm{e}-02$ \\
& $(\mathrm{q}=9.77 \mathrm{e}-01)$ & $(\mathrm{q}=8.59 \mathrm{e}-01)$ \\
CXCL10 & $-2.09 \mathrm{e}-03$ & $1.73 \mathrm{e}-02$ \\
& $(\mathrm{q}=6.98 \mathrm{e}-01)$ & $(\mathrm{q}=8.59 \mathrm{e}-01)$ \\
EGF & $3.57 \mathrm{e}-02$ & $1.09 \mathrm{e}-01$ \\
& $(\mathrm{q}=5.61 \mathrm{e}-01)$ & $(\mathrm{q}=8.59 \mathrm{e}-01)$ \\
G-CSF & $2.84 \mathrm{e}-03$ & $1.55 \mathrm{e}-01$ \\
& $(\mathrm{q}=9.77 \mathrm{e}-01)$ & $(\mathrm{q}=8.41 \mathrm{e}-01)$ \\
IL-17 & $-1.27 \mathrm{e}-02$ & $-4.90 \mathrm{e}-02$ \\
& $(\mathrm{q}=6.98 \mathrm{e}-01)$ & $(\mathrm{q}=8.59 \mathrm{e}-01)$ \\
IL-1RA & $1.16 \mathrm{e}-02$ & $3.72 \mathrm{e}-03$ \\
& $(\mathrm{q}=4.59 \mathrm{e}-01)$ & $(\mathrm{q}=9.81 \mathrm{e}-01)$ \\
IL-8 & $1.48 \mathrm{e}-02$ & $8.05 \mathrm{e}-02$ \\
& $(\mathrm{q}=6.98 \mathrm{e}-01)$ & $(\mathrm{q}=8.59 \mathrm{e}-01)$ \\
MPO & $4.25 \mathrm{e}-05$ & $-2.96 \mathrm{e}-03$ \\
& $(\mathrm{q}=9.79 \mathrm{e}-01)$ & $(\mathrm{q}=9.81 \mathrm{e}-01)$ \\
Periostin & $-6.95 \mathrm{e}-03$ & $-2.15 \mathrm{e}-01$ \\
& $(\mathrm{q}=7.82 \mathrm{e}-01)$ & $(\mathrm{q}=8.41 \mathrm{e}-01)$ \\
VEGF & $-4.23 \mathrm{e}-03$ & $-6.46 \mathrm{e}-02$ \\
& $(\mathrm{q}=7.04 \mathrm{e}-01)$ & $(\mathrm{q}=8.41 \mathrm{e}-01)$ \\
\hline & &
\end{tabular}

\footnotetext{
${ }^{a}$ Change in serum immune markers concentration determined before and after swimming in a chlorinated pool, adjusted for sex, age, and BMI. Serum concentrations were log-transformed in the regression model. qvalues were based on $p$ values reported by the regression models using the Benjamini-Hochberg procedure. ${ }^{\mathrm{b}}$ Total trihalomethanes measured in exhaled breath.

${ }^{\mathrm{c}}$ Change in energy expenditure (kilocalories).
} 
Table A.4. Percentage difference in serum immune marker concentrations before and after swimming in a chlorinated pool by gender.

\begin{tabular}{|c|c|c|c|c|}
\hline $\begin{array}{l}\text { Immune } \\
\text { marker }\end{array}$ & $\begin{array}{l}\text { \% change } \\
\text { all }^{\mathrm{a}}\end{array}$ & $\begin{array}{l}\text { \% change } \\
\text { men }^{\text {a }}\end{array}$ & $\begin{array}{l}\text { \% change } \\
\text { women }^{\mathrm{a}}\end{array}$ & $\begin{array}{l}p \text {-value for } \\
\text { interaction }^{b}\end{array}$ \\
\hline CCL11 & $\begin{array}{l}-7.15 \% \\
(q=9.48 e-02)\end{array}$ & $\begin{array}{l}-3.8 \% \\
(q=6.56 e-01)\end{array}$ & $\begin{array}{l}-10.3 \% \\
(q=3.31 e-02)\end{array}$ & $3.54 \mathrm{E}-01$ \\
\hline CCL2 & $\begin{array}{l}-6.29 \% \\
(q=9.48 e-02)\end{array}$ & $\begin{array}{l}-7.9 \% \\
(q=1.53 e-01)\end{array}$ & $\begin{array}{l}-4.7 \% \\
(q=4.19 e-01)\end{array}$ & $5.98 \mathrm{E}-01$ \\
\hline CCL22 & $\begin{array}{l}-7.28 \% \\
(q=4.00 e-04)\end{array}$ & $\begin{array}{l}-6.1 \% \\
(q=5.29 e-02)\end{array}$ & $\begin{array}{l}-8.4 \% \\
(q=1.20 e-02)\end{array}$ & 5.04E-01 \\
\hline CRP & $\begin{array}{l}-7.06 \% \\
(q=4.68 \mathrm{e}-05)\end{array}$ & $\begin{array}{l}-7.5 \% \\
(q=5.83 e-05)\end{array}$ & $\begin{array}{l}-6.6 \% \\
(q=4.90 e-02)\end{array}$ & 7.57E-01 \\
\hline CXCL10 & $\begin{array}{l}-13.03 \% \\
(q=6.34 \mathrm{e}-14)\end{array}$ & $\begin{array}{l}-12.3 \% \\
(q=5.63 e-06)\end{array}$ & $\begin{array}{l}-13.7 \% \\
(q=1.50 e-08)\end{array}$ & $6.20 \mathrm{E}-01$ \\
\hline EGF & $\begin{array}{l}-20.76 \% \\
(q=1.63 e-01)\end{array}$ & $\begin{array}{l}-5.1 \% \\
(q=8.02 e-01)\end{array}$ & $\begin{array}{l}-33.4 \% \\
(q=8.74 e-02)\end{array}$ & 2.07E-01 \\
\hline G-CSF & $\begin{array}{l}-0.74 \% \\
(q=9.38 \mathrm{e}-01)\end{array}$ & $\begin{array}{l}10.5 \% \\
(q=6.33 e-01)\end{array}$ & $\begin{array}{l}-10.5 \% \\
(q=4.42 e-01)\end{array}$ & $2.66 \mathrm{E}-01$ \\
\hline IL-17 & $\begin{array}{l}2.67 \% \\
(q=8.84 e-01)\end{array}$ & $\begin{array}{l}15.8 \% \\
(q=4.54 e-01)\end{array}$ & $\begin{array}{l}-8.6 \% \\
(q=4.19 e-01)\end{array}$ & $1.46 \mathrm{E}-01$ \\
\hline IL-1RA & $\begin{array}{l}20.16 \% \\
(q=4.18 e-06)\end{array}$ & $\begin{array}{l}30.6 \% \\
(q=2.39 e-06)\end{array}$ & $\begin{array}{l}10.8 \% \\
(q=9.13 e-02)\end{array}$ & $1.52 \mathrm{E}-02$ \\
\hline IL-8 & $\begin{array}{l}-12.53 \% \\
(q=2.00 e-03)\end{array}$ & $\begin{array}{l}10.7 \% \\
(q=3.34 e-02)\end{array}$ & $\begin{array}{l}-15.5 \% \\
(q=4.19 e-01)\end{array}$ & $2.86 \mathrm{E}-01$ \\
\hline MPO & $\begin{array}{l}-3.49 \% \\
(q=8.77 e-01)\end{array}$ & $\begin{array}{l}1.4 \% \\
(q=4.54 \mathrm{e}-01)\end{array}$ & $\begin{array}{l}1.0 \% \\
(q=4.96 e-01)\end{array}$ & $1.08 \mathrm{E}-01$ \\
\hline Periostin & $\begin{array}{l}1.21 \% \\
(q=3.05 e-01)\end{array}$ & $\begin{array}{l}6.0 \% \\
(q=7.19 e-01)\end{array}$ & $\begin{array}{l}-3.2 \% \\
(q=7.53 e-01)\end{array}$ & $8.29 \mathrm{E}-01$ \\
\hline VEGF & $\begin{array}{l}1.20 \% \\
(q=9.38 e-01)\end{array}$ & $\begin{array}{l}-16.1 \% \\
(q=1.11 \mathrm{e}-02)\end{array}$ & $\begin{array}{l}-8.9 \% \\
(q=1.45 e-01)\end{array}$ & 5.89E-01 \\
\hline
\end{tabular}

${ }^{a}$ Change in serum immune markers concentration determined before and after swimming in a chlorinated pool, adjusted for age, and BMI and stratified by sex. Serum concentrations were log-transformed in the regression model. q-values were based on $p$ values reported by the regression models using the BenjaminiHochberg procedure.

${ }^{\mathrm{b}} \mathrm{p}$-value for interaction term between age and sex added to a model not stratified by sex. 
Table A.5. Association between DBPs measured in exhaled breath and absolute change in concentration of serum immune markers ${ }^{\mathrm{a}}$.

\begin{tabular}{|c|c|c|c|c|c|}
\hline $\begin{array}{l}\text { Immune } \\
\text { marker }\end{array}$ & TTHM $^{b}$ & $\mathrm{Cl}_{3} \mathrm{CH}^{\mathrm{b}}$ & BDCM $^{b}$ & $\mathrm{DBCM}^{\mathrm{b}}$ & $\mathrm{Br}_{3} \mathrm{CH}^{\mathrm{b}}$ \\
\hline CCL11 & $\begin{array}{l}-4.92 \mathrm{e}-03 \\
(q=7.92 \mathrm{e}-02)\end{array}$ & $\begin{array}{l}-6.08 e-03 \\
(q=9.19 e-02)\end{array}$ & $\begin{array}{l}-2.99 e-02 \\
(q=5.09 e-02)\end{array}$ & $\begin{array}{l}-1.19 e-01 \\
(q=8.71 e-02)\end{array}$ & $\begin{array}{l}-4.17 e-01 \\
(q=3.40 e-01)\end{array}$ \\
\hline CCL2 & $\begin{array}{l}-3.18 e-03 \\
(q=2.39 e-01)\end{array}$ & $\begin{array}{l}-4.08 \mathrm{e}-03 \\
(q=2.34 \mathrm{e}-01)\end{array}$ & $\begin{array}{l}-1.76 \mathrm{e}-02 \\
(q=2.61 \mathrm{e}-01)\end{array}$ & $\begin{array}{l}-6.79 e-02 \\
(q=3.78 e-01)\end{array}$ & $\begin{array}{l}-2.46 e-01 \\
(q=7.02 e-01)\end{array}$ \\
\hline CCL22 & $\begin{array}{l}-4.95 e-03 \\
(q=3.10 e-04)\end{array}$ & $\begin{array}{l}-6.13 e-03 \\
(q=5.25 e-04)\end{array}$ & $\begin{array}{l}-3.01 \mathrm{e}-02 \\
(q=1.08 \mathrm{e}-04)\end{array}$ & $\begin{array}{l}-1.35 e-01 \\
(q=1.03 e-04)\end{array}$ & $\begin{array}{l}-6.44 e-01 \\
(q=6.05 e-04)\end{array}$ \\
\hline CRP & $\begin{array}{l}-4.40 \mathrm{e}-03 \\
(q=2.50 \mathrm{e}-04)\end{array}$ & $\begin{array}{l}-5.80 e-03 \\
(q=1.15 e-04)\end{array}$ & $\begin{array}{l}-2.18 e-02 \\
(q=1.73 e-03)\end{array}$ & $\begin{array}{l}-8.37 e-02 \\
(q=1.07 e-02)\end{array}$ & $\begin{array}{l}-3.59 e-01 \\
(q=5.49 e-02)\end{array}$ \\
\hline CXCL10 & $\begin{array}{l}-8.58 \mathrm{e}-03 \\
(q=1.05 \mathrm{e}-11)\end{array}$ & $\begin{array}{l}-1.09 e-02 \\
(q=1.25 e-11)\end{array}$ & $\begin{array}{l}-4.79 e-02 \\
(q=4.86 e-11)\end{array}$ & $\begin{array}{l}-2.05 e-01 \\
(q=8.65 e-10)\end{array}$ & $\begin{array}{l}-9.64 e-01 \\
(q=2.69 e-07)\end{array}$ \\
\hline EGF & $\begin{array}{l}-7.13 e-03 \\
(q=6.27 e-01)\end{array}$ & $\begin{array}{l}-9.06 e-03 \\
(q=6.28 e-01)\end{array}$ & $\begin{array}{l}-4.17 e-02 \\
(q=6.06 e-01)\end{array}$ & $\begin{array}{l}-1.48 e-01 \\
(q=7.51 e-01)\end{array}$ & $\begin{array}{l}-1.15 e-01 \\
(q=9.41 e-01)\end{array}$ \\
\hline G-CSF & $\begin{array}{l}1.69 e-04 \\
(q=9.94 e-01)\end{array}$ & $\begin{array}{l}2.74 e-04 \\
(q=9.94 e-01)\end{array}$ & $\begin{array}{l}3.69 e-04 \\
(q=9.94 e-01)\end{array}$ & $\begin{array}{l}-1.64 e-03 \\
(q=9.93 e-01)\end{array}$ & $\begin{array}{l}-1.44 e-01 \\
(q=9.41 e-01)\end{array}$ \\
\hline IL-17 & $\begin{array}{l}-1.59 e-03 \\
(q=9.79 e-01)\end{array}$ & $\begin{array}{l}-2.02 e-03 \\
(q=9.78 e-01)\end{array}$ & $\begin{array}{l}-9.46 e-03 \\
(q=9.60 e-01)\end{array}$ & $\begin{array}{l}-2.55 e-02 \\
(q=9.93 e-01)\end{array}$ & $\begin{array}{l}8.46 e-02 \\
(q=9.41 e-01)\end{array}$ \\
\hline IL-1RA & $\begin{array}{l}1.27 e-02 \\
(q=3.33 e-07)\end{array}$ & $\begin{array}{l}1.61 e-02 \\
(q=3.45 e-07)\end{array}$ & $\begin{array}{l}7.21 e-02 \\
(q=5.54 e-07)\end{array}$ & $\begin{array}{l}3.14 e-01 \\
(q=1.95 e-06)\end{array}$ & $\begin{array}{l}1.39 \mathrm{e}+00 \\
(q=1.80 \mathrm{e}-04)\end{array}$ \\
\hline IL-8 & $\begin{array}{l}-3.85 e-05 \\
(q=9.94 e-01)\end{array}$ & $\begin{array}{l}4.79 e-05 \\
(q=9.94 e-01)\end{array}$ & $\begin{array}{l}-2.28 \mathrm{e}-03 \\
(q=9.94 \mathrm{e}-01)\end{array}$ & $\begin{array}{l}-1.17 e-03 \\
(q=9.93 e-01)\end{array}$ & $\begin{array}{l}5.15 e-02 \\
(q=9.41 e-01)\end{array}$ \\
\hline MPO & $\begin{array}{l}7.21 e-04 \\
(q=3.98 e-01)\end{array}$ & $\begin{array}{l}9.54 e-04 \\
(q=3.67 e-01)\end{array}$ & $\begin{array}{l}3.48 e-03 \\
(q=5.31 e-01)\end{array}$ & $\begin{array}{l}1.36 e-02 \\
(q=6.38 e-01)\end{array}$ & $\begin{array}{l}6.16 e-02 \\
(q=7.46 e-01)\end{array}$ \\
\hline Periostin & $\begin{array}{l}-4.32 \mathrm{e}-04 \\
(q=9.94 \mathrm{e}-01)\end{array}$ & $\begin{array}{l}-7.71 e-04 \\
(q=9.94 e-01)\end{array}$ & $\begin{array}{l}-2.25 e-04 \\
(q=9.94 e-01)\end{array}$ & $\begin{array}{l}2.36 e-02 \\
(q=9.93 e-01)\end{array}$ & $\begin{array}{l}2.51 \mathrm{e}-01 \\
(\mathrm{q}=9.41 \mathrm{e}-01)\end{array}$ \\
\hline VEGF & $\begin{array}{l}-8.53 e-03 \\
(q=2.25 e-03)\end{array}$ & $\begin{array}{l}-1.07 e-02 \\
(q=2.73 e-03)\end{array}$ & $\begin{array}{l}-4.95 e-02 \\
(q=1.73 e-03)\end{array}$ & $\begin{array}{l}-2.16 e-01 \\
(q=2.74 e-03)\end{array}$ & $\begin{array}{l}-1.02 e+00 \\
(q=8.20 e-03)\end{array}$ \\
\hline
\end{tabular}

${ }^{a}$ Change in serum immune markers concentration determined before and after swimming in a chlorinated pool, adjusted for sex, age, and BMI. Serum concentrations were log-transformed in the regression model. qvalues were based on $\mathrm{p}$ values reported by the regression models using the Benjamini-Hochberg procedure. ${ }^{\mathrm{b}}$ Total trihalomethanes (TTHM), bromodichloromethane (BDCM), bromoform $\left(\mathrm{Br}_{3} \mathrm{CH}\right)$, chloroform $\left(\mathrm{CHCl}_{3}\right)$, dibromochloromethane (DBCM). 
Table A.6. Detection rate for all markers included in the study and odds ratio for detection for markers with at least 10 detects and 10 non-detects.

\begin{tabular}{lllll} 
Marker & $\begin{array}{l}\text { Detects/ } \\
\text { non-detects }\end{array}$ & $\begin{array}{l}\text { Included in } \\
\text { main analysis }\end{array}$ & OR $(95 \% \text { Cl })^{\mathbf{c}}$ & $\boldsymbol{p ~ v a l u e ~}^{\mathbf{d}}$ \\
\hline CCL11 & $83 / 35$ & Yes & $0.54(0.24-1.24)$ & 0.15 \\
CXCL1 & $12 / 106$ & No & $0.46(0.13-1.63)$ & 0.23 \\
G-CSF & $103 / 15$ & Yes & $0.62(0.20-1.90)$ & 0.40 \\
IL-6 & $15 / 103$ & No & $3.45(0.98-12.12)$ & 0.05 \\
TNF- $\alpha$ & $26 / 92$ & No & $1.23(0.51-2.98)$ & 0.65
\end{tabular}

${ }^{\mathrm{a}}$ Frequency of samples in which markers were detected.

${ }^{b}$ Indicator for the inclusion of this marker in the main analyses of this study.

${ }^{c}$ Odds ratio and $95 \%$ confidence interval of detecting a marker post swimming versus pre swimming. Estimated for markers with at least 10 detects and 10 non-detects using a logistic regression model, adjusted for age, sex, and $\mathrm{BMI}$.

${ }^{d} p$-value associated with the odds ratio of detecting a marker post swimming versus pre swimming. 
Table A.7. Association between trichloramine measured in air and absolute change in concentration of serum immune markers ${ }^{\mathrm{a}}$.

\begin{tabular}{|c|c|c|}
\hline $\begin{array}{l}\text { Immune } \\
\text { marker }\end{array}$ & Trichloramine $^{\mathrm{a}}$ & $\begin{array}{l}\text { Trichloramine } \\
\text { adjusted for Kcal }\end{array}$ \\
\hline CCL11 & $\begin{array}{l}2.07 e-03 \\
(q=7.69 e-01)\end{array}$ & $\begin{array}{l}1.60 \mathrm{e}-03 \\
(q=6.12 \mathrm{e}-01)\end{array}$ \\
\hline CCL2 & $\begin{array}{l}3.29 \mathrm{e}-03 \\
(q=8.45 \mathrm{e}-01)\end{array}$ & $\begin{array}{l}2.96 e-03 \\
(q=8.18 e-01)\end{array}$ \\
\hline CCL22 & $\begin{array}{l}1.07 e-02 \\
(q=8.45 e-01)\end{array}$ & $\begin{array}{l}1.08 \mathrm{e}-02 \\
(q=5.95 e-01)\end{array}$ \\
\hline CRP & $\begin{array}{l}-1.90 e-02 \\
(q=1.88 e-01)\end{array}$ & $\begin{array}{l}-1.81 e-02 \\
(q=6.12 e-01)\end{array}$ \\
\hline CXCL10 & $\begin{array}{l}2.83 e-03 \\
(q=7.69 e-01)\end{array}$ & $\begin{array}{l}2.50 \mathrm{e}-03 \\
(q=6.91 \mathrm{e}-01)\end{array}$ \\
\hline EGF & $\begin{array}{l}7.84 e-03 \\
(q=8.45 e-01)\end{array}$ & $\begin{array}{l}7.00 e-03 \\
(q=9.32 e-01)\end{array}$ \\
\hline G-CSF & $\begin{array}{l}-1.10 e-02 \\
(q=7.69 e-01)\end{array}$ & $\begin{array}{l}-1.08 e-02 \\
(q=9.33 e-01)\end{array}$ \\
\hline IL-17 & $\begin{array}{l}-1.57 e-02 \\
(q=8.45 e-01)\end{array}$ & $\begin{array}{l}-1.58 \mathrm{e}-02 \\
(q=9.32 \mathrm{e}-01)\end{array}$ \\
\hline IL-1RA & $\begin{array}{l}6.52 \mathrm{e}-03 \\
(q=8.45 \mathrm{e}-01)\end{array}$ & $\begin{array}{l}6.94 e-03 \\
(q=8.87 e-01)\end{array}$ \\
\hline IL-8 & $\begin{array}{l}-3.58 \mathrm{e}-05 \\
(q=8.45 \mathrm{e}-01)\end{array}$ & $\begin{array}{l}-6.55 e-05 \\
(q=6.91 e-01)\end{array}$ \\
\hline MPO & $\begin{array}{l}-3.83 e-03 \\
(q=4.40 e-01)\end{array}$ & $\begin{array}{l}-3.83 e-03 \\
(q=5.95 e-01)\end{array}$ \\
\hline Periostin & $\begin{array}{l}-2.70 e-02 \\
(q=8.45 e-01)\end{array}$ & $\begin{array}{l}-2.72 \mathrm{e}-02 \\
(q=9.32 \mathrm{e}-01)\end{array}$ \\
\hline VEGF & $\begin{array}{l}-1.18 e-02 \\
(q=8.45 e-01)\end{array}$ & $\begin{array}{l}-1.28 \mathrm{e}-02 \\
(q=8.83 \mathrm{e}-01)\end{array}$ \\
\hline
\end{tabular}

${ }^{a}$ Change in serum immune markers concentration determined before and after swimming in a chlorinated pool, adjusted for sex, age, and BMI. Serum concentrations were log-transformed in the regression model. qvalues were based on $\mathrm{p}$ values reported by the regression models using the Benjamini-Hochberg procedure. ${ }^{\mathrm{b}}$ Change per unit change in trichloramine concentration measured in air $\left(\mu \mathrm{g} / \mathrm{m}^{3}\right)$.

${ }^{c}$ Analyses additionally adjusted for change in energy expenditure (Kcal; kilocalories). 